\title{
Agências do Artificial e do Humano: Uma análise de noções do humano na Inteligên- cia Artificial a partir de perspectivas sociais e culturais
}

\author{
Rafael Wild
}

Orientadora: Profa. Dra. Maria Cristina Villanova Biazus

Coorientadora: Profa. Dra. Cleci Maraschin

Banca: Prof. Dr. Eliseo Berni Reategui (PGIE/UFRGS), Prof. Dr. Arlei Sander Damo (UFRGS), Prof. Dr. Rafael Vetromille Castro (UFPel)

Data da defesa: 02 de junho de 2011

Esta tese analisa noções construídas sobre o ser humano que são apropriadas com fins tecnológicos, em sistemas computacionais produzidos por praticantes da Inteligência Artificial. Foi desenvolvido com base em um trabalho de campo de observação participante junto a grupos de pesquisa acadêmico na área de Inteligência Artificial, um brasileiro e outro europeu (português). O trabalho articula-se com as demandas da Informática na Educação ao focar, de maneira não estrita, projetos com caráter pedagógico. O presente estudo, através dos significados e as práticas observadas a partir de dentro dos grupos, procurou compreender o conhecimento do participante enquanto pertencente a uma cultura própria e peculiar, e a lógica interna desta cultura. Foram interrogados com especial atenção os artefatos produzidos: sistemas computacionais, investidos das características funcionais desejadas pelos participantes, e materializando suas práticas e premissas. Observou-se como emoção, conhecimento, cultura, e agência, entre outros, são conceituados, estabelecidos e colocados em práticas como categorias do humano, não apenas como definições expressas em texto, mas como materializadas em artefatos e em expectativas sobre o encontro entre estes artefatos e seus usuários. Foi consistentemente trabalhado o "colocar em perspectiva" das práticas e noções próprias do campo estudado, a partir de ferramentas teóricas propostas pelos Estudos de Ciência e Tecnologia, em especial por B. Latour, L. Suchman e D. Forsythe. As práticas e noções, no campo abordado, são conhecimento científico e tecnológico, com estatuto próprio e estabelecido como válido e legítimo; em relação a isto, foi sistematicamente buscada a colocação desta validade e desta legitimidade em perspectiva, mostrando como esta validade relaciona-se com a forma de produção e legitimação, e como esta produção e legitimação podem ser vistas de outras formas. Espera-se, com estes resultados, contribuir para um diálogo mais sofisticado dentro da Informática na Educação entre as práticas tecnológicas, a Ciência da Computação e Inteligência Artificial, e a aplicação social e pedagógica destas práticas.

Palavras-chave: Inteligência Artificial. Estudos de Ciência e Tecnologia. Computação Afetiva. Humano. Emoção na Inteligência Artificial.

\section{Referência:}

WILD, Rafael. Agências do Artificial e do Humano: Uma análise de noções do humano na Inteligência Artificial a partir de perspectivas sociais e culturais. Orientadora: Maria Cristina Villanova Biazus. Coorientadora: Cleci Maraschin. 2011. Tese (Doutorado) - Programa de Pós-Graduação em Informática na Educação, Centro de Estudos Interdisciplinares em Novas Tecnologias da Educação, Universidade Federal do Rio Grande do Sul, 2011, Porto Alegre, BR-RS. Membros da Banca Examinadora: Eliseo Berni Reategui (PGIE/UFRGS), Arlei Sander Damo (UFRGS), Rafael Vetromille Castro (UFPel). Data da defesa: 02/06/2011. 